\title{
Human-landing rate, gonotrophic cycle length, survivorship, and public health importance of Simulium erythrocephalum in Zaragoza, northeastern Spain
}

\author{
Ignacio Ruiz-Arrondo ${ }^{1,2^{*}+}$, Javier A. Garza-Hernández ${ }^{3,4 \dagger}$, Filiberto Reyes-Villanueva ${ }^{3}$, Javier Lucientes-Curdi ${ }^{1}$
} and Mario A. Rodríguez-Pérez ${ }^{3}$

\begin{abstract}
Background: Simulium (Boophthora) erythrocephalum (De Geer, 1776) is one of the blackfly species responsible for major public health problems in Europe. Blackfly outbreaks of this species are becoming more frequent, threatening public health in Spain. In the present study, bionomic parameters of S. erythrocephalum in northeastern Spain were estimated.

Methods: Simulium erythrocephalum was collected from May through June 2015 in Zaragoza, Spain, using the human-landing-collection (HLC) method. Daily pattern of total and parous landing activity was estimated, as was the gonotrophic cycle (GC) length and survivorship (S) rate, using time series analysis.

Results: Host-seeking females of S. erythrocephalum showed a bimodal human-landing activity pattern, with a minor and major peak at dawn and dusk, respectively; there was a significant negative association between human daily landing rate and temperature $(P=0.003)$ and solar radiation $(P<0.001)$. Overall, a daily landing rate (DLR) of 34 lands/person/day was estimated. Series of sequential data analysis on parity showed the highest significant $(P<0$. 001) correlation indices ( $r=0.45$ and $r=0.39$ for raw and filtered data) for a 2-day time lag, indicating that the GC length corresponded to 2 days. Daily survivorship and parity rate were 0.85 and 0.72 , respectively.

Conclusions: Simulium erythrocephalum was confirmed as a nuisance species in Zaragoza, using the HLC method for the first time in Spain. The data offer insights into the ecology of S. erythrocephalum, which can improve management strategies of this pest in Spain.
\end{abstract}

Keywords: Blackfly, Simulium erythrocephalum, Human landing activity, Parous rate, Gonotrophic cycle, Survival rate, Host-seeking behavior

\section{Background}

Blood-sucking blackflies (Diptera: Simuliidae) are important to medical and veterinary health. As vectors of disease agents (leucocytozoonosis, human onchocerciasis, mansonellosis, bovine onchocerciasis and the virus

\footnotetext{
* Correspondence: iruizarr@unizar.es

${ }^{\dagger}$ Equal contributors

'Departamento de Patología Animal, Facultad de Veterinaria, Universidad de Zaragoza, Zaragoza, Spain

${ }^{2}$ Centro de Rickettsiosis y Enfermedades Transmitidas por Artrópodos Vectores, Centro de Investigación Biomédica de La Rioja (CIBIR), La Rioja, Spain

Full list of author information is available at the end of the article
}

that causes vesicular stomatitis) [1], they also cause intolerable nuisances because of their abundance and habit of swarming and biting [1]. Blackflies introduce salivary molecules into the biting lesion, which are responsible for severe allergic reactions [2, 3]. In Spain, blackfly populations have expanded recently. The city of Zaragoza in northeastern Spain, with about 700,000 inhabitants, is the centre of an emerging public-health problem because of the abundance of blackflies near the rivers [4]. In the city of Zaragoza, the number of medical consultations due to arthropod bites increased by more than $200 \%$ during 2011 and $2012(14,146$ and 18,000, 
respectively), compared to previous years, 2009 and 2010 (4210 and 4512, respectively) (data from the Public Health Department, Government of Aragon). In spite of the numerous medical reports concerning bites could be caused by any arthropod (e.g. bees, wasps, mosquitoes, spiders), all entomological studies carried out during the outbreaks in 2011 and 2012 demonstrated that the aforementioned biting increment was due to the abundance of blackflies at the Ebro riverbanks of the city of Zaragoza [4, 5]. Of the 55 species known from Spain $[6,7]$, S. erythrocephalum is assumed to cause the majority nuisance of problems in the country because its immature stages are commonly found together with non-human biting species (subgenus Wilhelmia) in rivers near the areas of nuisance reports [4]. The current study is the first to use the human-landing-collection (HLC) technique for collecting blackflies in Spain.

Bionomics of blackflies, in particular, spatial and temporal population dynamics of parous host-seeking females, are well studied in primary vector species of onchocerciasis. This type of study was crucial in onchocerciasis control and elimination programmes in Latin America and Africa. Although S. erythrocephalum does not share a geographical distribution with endemic areas for Onchocerca volvulus, some laboratory studies have shown this species could potentially be a competent vector of O. volvulus [8]. In addition, this species has been incriminated as a natural vector of O. lienalis [9] and O. gutturosa [10] in cattle in Europe.

Blackfly control programmes require entomological studies to assess the magnitude of the problem and implement optimal strategies of monitoring, surveillance and control [4]. Recently, anthropophilic and zoophilic blackfly species triggered outbreaks in different regions in Spain [11], but no data was available on the factor(s) that may have caused the outbreaks or on the bionomics of the adults of S. erythrocephalum. Thus, we present an entomological study of the bionomics of $S$. erythrocephalum. The length of the gonotrophic cycle, using time series analysis, daily pattern of humanlanding activity and its correlation with environmental parameters, daily survivorship and parity of $S$. erythrocephalum were studied in northeastern Spain. The bionomics of S. erythrocephalum are discussed in relation to its role as an emerging public-health nuisance in Spain.

\section{Methods}

\section{Study area}

The study was conducted in the district of "La Cartuja", a rural suburb close to Zaragoza in northeastern Spain. The sampling plot was $115 \mathrm{~m}$ from the riverbanks of the Ebro River $\left(41^{\circ} 36^{\prime} 55.97^{\prime \prime} \mathrm{N}, 00^{\circ} 49^{\prime} 52.57^{\prime \prime} \mathrm{W}, 185\right.$ metres above sea level, masl; Fig. 1c). It is a semi-naturalized area, $5.4 \mathrm{~km}$ downstream from a small dam that marks the end of the urbanised area of the city. The banks of the river are partially vegetated with typical species of riverside groves such as Populus spp. and Salix spp. and other shrub species such as Rubus spp. and Tamarix spp., and mainly surrounded by irrigated lands in the Valley Ebro, such as corn and lucerne.

In a preliminary survey conducted during May 2015, larvae, pupae, and adults of blackflies were collected along the Ebro River downstream from Zaragoza to select the best sampling plots to ensure collection of preimaginal stages and adults of S. erythrocephalum. Large larval and pupal populations of S. erythrocephalum have been documented recently in the area [4]. No larval control was performed during 2015 in this stretch of the river, which could have affected the present study.

\section{Daily pattern of human-landing activity of host-seeking $S$.} erythrocephalum

Two collectors of flies (IRA and JAGH, served as volunteers) were situated 75 meters apart; both fly collectors were under the shadow of a tree to catch wild hostseeking females of S. erythrocephalum and other blackfly species (Fig. 1c). The fly collectors were not smokers and did not wear cologne or any lotion that could influence the host-seeking behavior of blackflies. The fly collectors wore dark short pants and light short-sleeved shirts and collected blackflies on exposed skin. Hostseeking females were captured while they were landing or attempting to feed on the human collector, and were placed in $75 \times 12 \mathrm{~mm}$ plastic polystyrene tubes (Thermo Scientific, PA, USA) [12]. Tubes with flies were kept in Ziploc storage bags, maintained in gel-ice portable coolers during the field work, and transported to the laboratory where the flies were dissected to determine the gonotrophic status and the total number of nulliparous and parous flies. Sampling was carried out during the first $40 \mathrm{~min}$ of each hour starting at 06:30 and ending at 20:30 (Central European Summer Time - UTC + 2 h) for 12 consecutive days from May 29 through June 9, 2015. The collection period was selected to coincide with the sunrise (06:29) and sunset (21:38) at this latitude during the first day of the study in May. Sampling ended at 20:30 due to the absence of sunlight. Collectors were rotated daily between the two sampling sites to avoid position bias [13].

To determine the daily patterns of human-landing activity, the human-landing rate per hour was calculated as the total number of flies caught during each sampling period divided by the number of fly collectors, and it was expressed as the number of lands/person/hour. A proportion of blackflies land on the skin but they do not bite; therefore, the landing rate represents a maximum possible biting rate. A generalised linear mixed model 


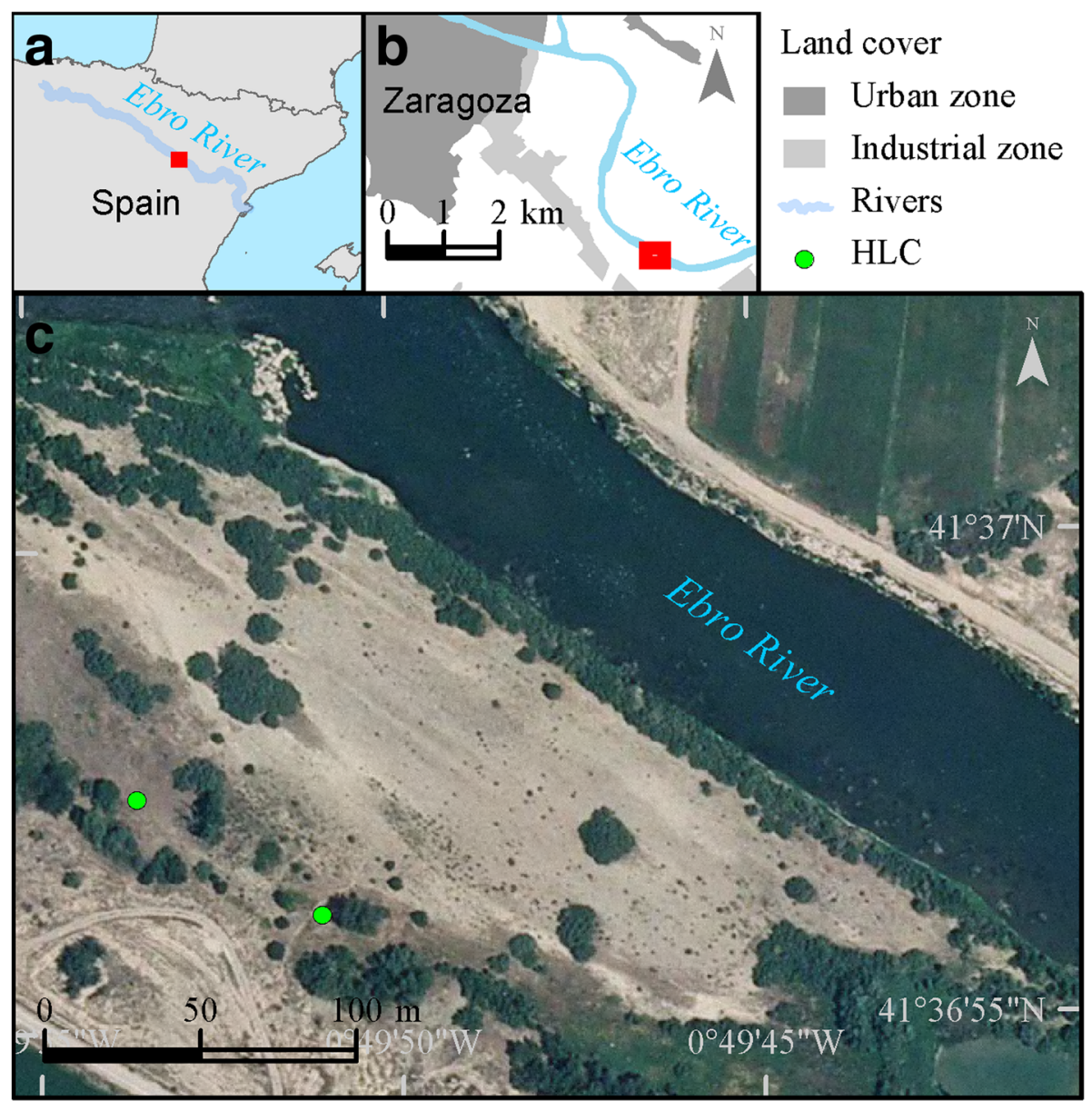

Fig. 1 District of La Cartuja in the city of Zaragoza, Spain. In a, red square indicates the location of the city of Zaragoza in Spain. In $\mathbf{b}$, red rectangle indicates the sampling site for host-seeking S. erythrocephalum females. In c, green circles indicate the position of the human-landing collectors (HLC)

(GLIMMIX) in SAS (SAS software version $9.413 \mathrm{w} 18$ Media) was used to fit the human-landing rate during the 12 days to a negative binomial distribution, and the least square means (LSM) of the sampling periods were compared. In addition, correlation and multiple linear regression analyses were performed to associate meteorological variables and sampling periods during the 12 days of the study.

\section{Meteorological variables}

Weather variables such as temperature $\left({ }^{\circ} \mathrm{C}\right)$ and relative humidity (\%) were recorded using a digital weather station (EasyWeather ${ }^{\mathrm{m}}$, Model PCE-FWS20, Albacete, Spain) that was placed under a tree at the sampling site. Wind speed $(\mathrm{km} / \mathrm{h})$, rainfall $\left(\mathrm{mm}^{3}\right)$, and solar radiation $\left(\mathrm{W} / \mathrm{m}^{2}\right)$ were obtained from the nearest regional meteorological station in Pastriz (Zaragoza, Spain; 41 $35^{\prime}$ $39.40^{\prime \prime} \mathrm{N}, 00^{\circ} 43^{\prime} 49.48^{\prime \prime} \mathrm{W}, 192$ masl) $8.6 \mathrm{~km}$ from the sampling site. All weather variables were recorded daily and hourly from 06:00 to 22:00. Daily landing patterns depend on meteorological variables; hence, the data were normalised with the function $\operatorname{Ln}(x+1)$, and a multiple linear regression was used to identify which variables were correlated with the daily landing pattern.

\section{Gonotrophic cycle length and survivorship rate of host- seeking S. erythrocephalum}

The length of the gonotrophic cycle and survivorship rate of S. erythrocephalum were determined using an additional sampling of 10 consecutive days besides the 12 days of sampling for human-landing activity (i.e. June 10-19, 2015), making a total of 22 collection days for data analysis. However, sampling was carried out only from 18:30 to 20:30, which covered the main peak of daily human-landing activity. HLC was carried out as previously described. All specimens of S. erythrocephalum were dissected individually in a $0.85 \%$ saline solution and classified as nulliparous or parous based on absence or presence of sacculate dilatations and follicular relics in the ovarian tunic [14].

For data analysis, time series of 22 days were created. Each time series was constructed using the number of 
parous females $(\mathrm{Pt})$ as the dependent variable (Y-axis) and the total number of females (Tf) as the independent variable (X-axis). Then, data were analysed by Mutero's and Birley's procedure [15], using the Auto Regressive Integrated Moving Average procedure (ARIMA procedure in SAS) to predict the length of the gonotrophic cycle in days. The $\mathrm{r}$-coefficient for day 0 represents the correlation between $\mathrm{Pt}$ and $\mathrm{Tf}$ data pairs from flies captured the same day. The $\mathrm{r}$-coefficient for a day was obtained by pairing daily $\mathrm{Pt}$ data with the corresponding Tf data of all previous days. It was assumed that a significant cross-correlation coefficient $(r)$ between the time series expresses a time delay $(\mathrm{u})$ equivalent to the length of the gonotrophic cycle. The highest significant crosscorrelation coefficient $(r)$ obtained after day zero $(u=0)$ indicated the number of days per gonotrophic cycle of wild populations of S. erythrocephalum. To avoid false peaks in the correlation coefficients caused by uncontrolled factors such as inconsistency in day-to-day collections or collections dominated by disturbances, the original data were transformed (filtration) by an autoregressive equation with a time delay of 1 day of $Z_{T}=X_{T}$ - $\beta$ (Xt-1), where $Z_{T}$ is the transformed data, $X_{T}$ is the time series to be filtered (number of parous females collected in $\mathrm{t}$ day), $\mathrm{Xt}-1$ is the total females collected before $t$ day, and $\beta$ is the estimated auto-regressive parameter (value of the slope of the linear regression applied to the data) [16]. Daily parity rate (DPR) was estimated as the ratio between $\Sigma$ Pf and $\Sigma$ Tf.

The survivorship or daily survival rate (DSR) was estimated by Davidson's method [17], using the proportion of parous females in a population and calculated using the following equation:

$$
D S R=\sqrt[x]{D P R},
$$

where $\mathrm{x}$ is the length of the gonotrophic cycle in days. In addition, the survivorship rate per gonotrophic cycle was calculated by the cross-correlation method [15] employing the equation:

$$
\sigma(\mathrm{x}, \mathrm{y})=\frac{\sum_{i=1}^{N}\left(x i-\frac{\Sigma x}{N}\right)\left(y-\frac{\Sigma y}{N}\right)}{N=1} / \sigma_{x}=\frac{\sum\left(x-\frac{\Sigma x}{N}\right)^{2}}{N},
$$

where $\mathrm{x}$ is the total number of females and $\mathrm{y}$ is the number of parous females.

\section{Confirmation of gonotrophic cycle by oogenesis study}

To confirm the length of the gonotrophic cycle, Christophers's stages $[18,19]$ were recorded using 32 blood-engorged wild females of $S$. erythrocephalum fed by the two fly collectors. Flies were kept in the dark and maintained at $28{ }^{\circ} \mathrm{C}$ in plastic tubes, as described by Figueroa et al. [12]. Individual flies were dissected immediately after blood feeding at 6-h intervals for two consecutive days. Dissections of ovaries were made on glass slides containing a drop of $1 \times$ phosphate buffer solution (1× PBS). Ovaries were examined under phase-contrast microscopy. At least, three flies were examined for each period. Follicular development was characterised using Christophers's stages as reported by Cupp \& Collins [14].

\section{Results}

\section{Daily pattern of human-landing activity}

A total of 806 host-seeking females of S. erythrocephalum was caught. A DLR of 33.58 lands/person/day for $S$. erythrocephalum was estimated for Zaragoza. The highest daily landing rate was on May 29 (1st day) with 105.5 lands/person and the lowest on June 2 (5th day) with 4.5 lands/person.

The collection data (blackflies caught by two HLC) conformed to a negative binomial distribution and were thus examined using a general linear mixed model. The model used blackflies caught as the dependent variable and sampling day, fly collector, and sampling period as the independent variables. The model fits the data well ( $-2 \log$ likelihood value of 693.58 and a Pearson $\chi^{2} /$ degrees of freedom ratio of $\sim 1$ indicating no evidence for overdispersion). There was a significant association with sampling days $(P<0.001)$ and sampling period $(P<0.001)$. No evidence was found for an association of the two fly collectors with the number of catches $(P=0.815)$. Most lands were located on uncovered parts of the legs, but few on the arms.

Human-landing activity of host-seeking females of $S$. erythrocephalum showed a bimodal pattern, with the first peak at sunrise between 06:30 and 08:10 (representing $23.1 \%$ of the lands) and the second peak between 18:30 and 21:10 (with $66.9 \%$ of the lands); the remaining landing activity occurred between 08:30 and 18:10 (10.0\%) (Fig. 2). The parity rates of S. erythrocephalum, recorded during the first and second landing period, were $55.9 \%$ and $78.1 \%$, respectively (Fig. 2 ). A high proportion (data not shown) of parous females, collected between 18:30 and 21:10, presented large sac-like follicular dilatations, indicating that oviposition had occurred within the previous $2-4 \mathrm{~h} \mathrm{[14]}$.

\section{Effect of meteorological variables on the daily human- landing pattern (DHLP)}

From all explanatory variables (day, hour, temperature, relative humidity, wind speed, rainfall, and solar radiation), the best model to estimate the DHLP included temperature $(\mathrm{T})(P=0.003)$ and solar radiation (SR) $(P<0.001)$. The multiple linear regression model was $\operatorname{Ln}(\mathrm{DHLP}+1)=6.904-1.567 \mathrm{Ln}(\mathrm{T}+1)-0.224 \mathrm{Ln}$ $(\mathrm{SR}+1)\left(R^{2}=0.474, P<0.001\right)$. 


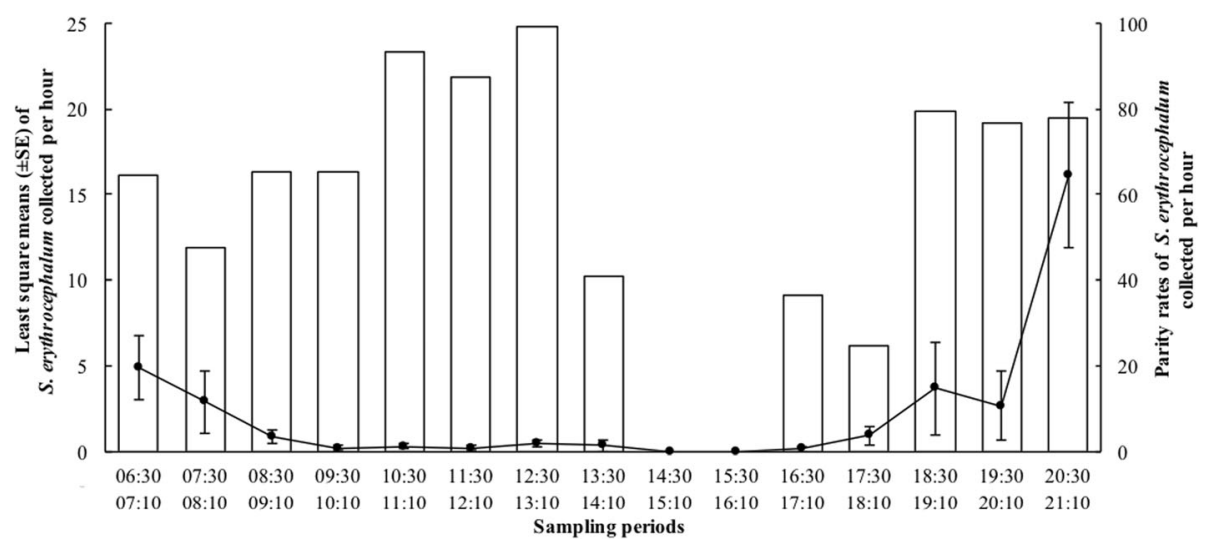

Fig. 2 Bimodal daily landing activity pattern (line) and parity rates (bars) of host-seeking $S$. erythrocephalum females. For the $Y_{1}$ axis, the values are expressed as the least square means \pm standard error of the number of flies attracted by human-landing collectors, whereas for the $Y_{2}$ axis, the values are the parity rates expressed as percentages

The landing activity of S. erythrocephalum was negatively associated with increasing temperature and solar radiation (Fig. 3). Following the experiments on daily landing rate and GC and during the first week of July 2015, a heat wave in Spain increased the average temperatures. During this period, a mean of $32.15{ }^{\circ} \mathrm{C}$ was recorded during the second peak (18.30-20.30), $7.35{ }^{\circ} \mathrm{C}$ more than the usual average $\left(24.8{ }^{\circ} \mathrm{C}\right)$ observed in the study. Blood-sucking females of S. erythrocephalum were not active at elevated temperatures; no specimens were caught by HLC.

\section{Estimation of gonotrophic cycle length and survivorship rate}

A total of 875 females were collected, with a DPR of 0.72 (635 parous females). The highest capture occurred on day 2, with 128 females (86 parous females), and the lowest capture occurred on day 17, with only five females (4 parous females) (Table 1). The first significant $(P<0.05)$ correlation peak appeared on day 2 , using filtered data. The cross-correlation coefficients for raw and filtered data were $r=0.45$ and $r=0.39$ for this time delay $(\mathrm{u}=2)$, respectively. Using Davidson's formula [17],

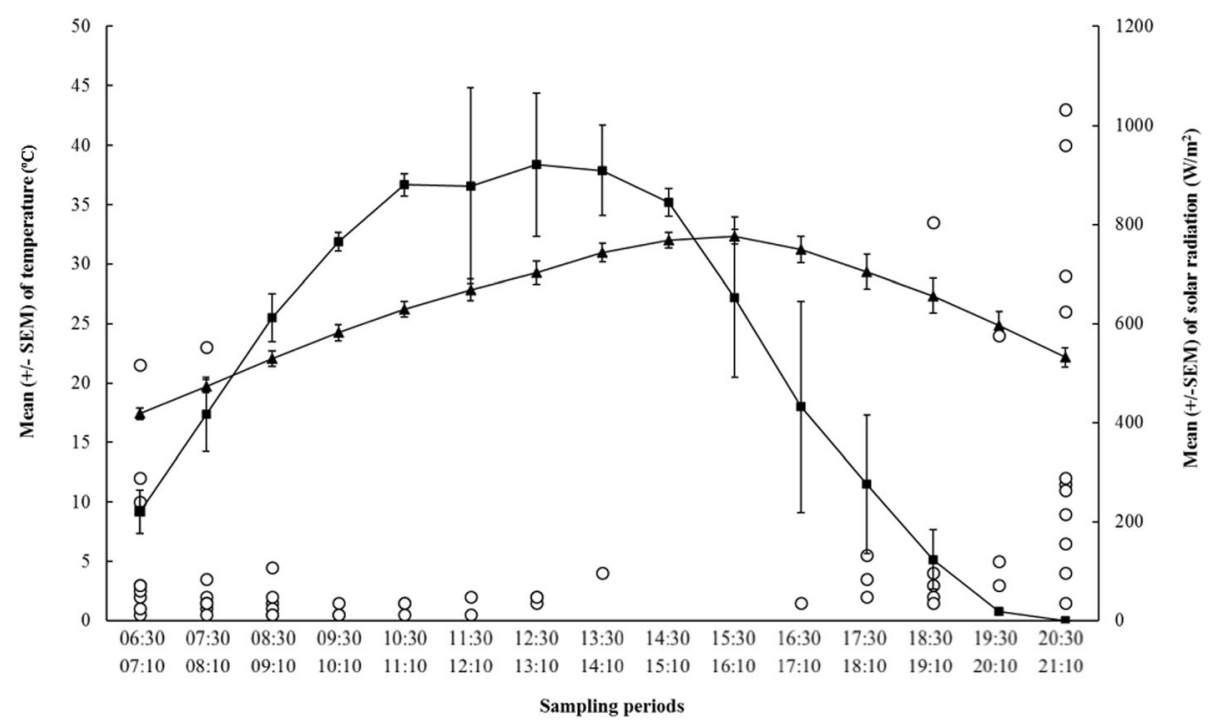

Fig. 3 Relationship between the number of flies collected per hour of host-seeking S. erythrocephalum females and temperature and solar radiation. The white circles indicate the mean number of flies collected over 12 days. The black line with black triangles indicates the mean temperature $\left({ }^{\circ} \mathrm{C}\right)$, and the black line with black squares indicates the solar radiation $\left(\mathrm{W} / \mathrm{m}^{2}\right)$ 
Table 1 Number of captured S. erythrocephalum females in Zaragoza, Spain

\begin{tabular}{|c|c|c|c|}
\hline Collection day & $\begin{array}{l}\text { Total no. } \\
\text { of females }\end{array}$ & $\begin{array}{l}\text { No. of parous } \\
\text { females }\end{array}$ & Daily parity rate \\
\hline 1 & 98 & 67 & 0.55 \\
\hline 2 & 128 & 86 & 0.67 \\
\hline 3 & 90 & 66 & 0.69 \\
\hline 4 & 31 & 25 & 0.70 \\
\hline 5 & 9 & 6 & 0.70 \\
\hline 6 & 42 & 37 & 0.72 \\
\hline 7 & 28 & 18 & 0.71 \\
\hline 8 & 18 & 17 & 0.72 \\
\hline 9 & 52 & 43 & 0.73 \\
\hline 10 & 58 & 43 & 0.73 \\
\hline 11 & 22 & 18 & 0.74 \\
\hline 12 & 11 & 6 & 0.73 \\
\hline 13 & 13 & 8 & 0.73 \\
\hline 14 & 47 & 31 & 0.72 \\
\hline 15 & 13 & 9 & 0.72 \\
\hline 16 & 16 & 10 & 0.72 \\
\hline 17 & 5 & 4 & 0.72 \\
\hline 18 & 31 & 21 & 0.72 \\
\hline 19 & 47 & 32 & 0.72 \\
\hline 20 & 39 & 27 & 0.71 \\
\hline 21 & 27 & 23 & 0.72 \\
\hline 22 & 50 & 38 & 0.72 \\
\hline Totals & 875 & 635 & na \\
\hline
\end{tabular}

Abbreviation: na, not applicable we estimated the daily survival rate to be 0.85 , using a daily parity rate of 0.72 (Table 1 ).

\section{Confirmation of gonotrophic cycle length by oogenesis}

A general chronology of post-feeding changes in the ovary (Fig. 4) is described as follows: (i) $0 \mathrm{~h}$ : the blood meal occurred; (ii) $6 \mathrm{~h}$ post-feeding: the ovaries were in stage III, with the nucleus no longer visible and the yolk filling about $30-40 \%$ of the follicular space; the nurse cells were crowded in the distal portion of the follicle (Fig. 4a); (iii) 12 to $36 \mathrm{~h}$ post-feeding: the ovaries were in stage IV, namely, with yolk present throughout the follicular space and the nurse cells compacted distally (Fig 4b); and (iv) 42 to $48 \mathrm{~h}$ post-feeding: the ovaries were in stage $\mathrm{V}$, with a true chorion and a visible micropyle (Fig. 4c), which indicated the end of oogenesis $[14,20]$.

\section{Discussion}

The current study provides evidence that S. erythrocephalum could be a major responsible species for the blackfly nuisances in Zaragoza [5]. Larvae and pupae shared the breeding site with three other species, all in the subgenus Wilhelmia: S. sergenti, S. lineatum, and S. equinum. An association of S. erythrocephalum with Wilhemia spp. is common in other Spanish and European rivers [21, 22]. Species of Wilhelmia might be annoying for humans, as they fly about the faces of people, although humans are not their natural host. In Zaragoza, only S. erythrocephalum was captured using HLC. Similar biting habits have been reported including bites on the neck [23, 24].

The daily human-landing rate of 34 lands/person/day for S. erythrocephalum in Zaragoza indicates that this species is highly anthropophilic in Spain. Zivkovic [23] reported biting activity of $S$. erythrocephalum for all species of domestic animals. However, host preferences of S. erythrocephalum seem to differ, depending on the region of
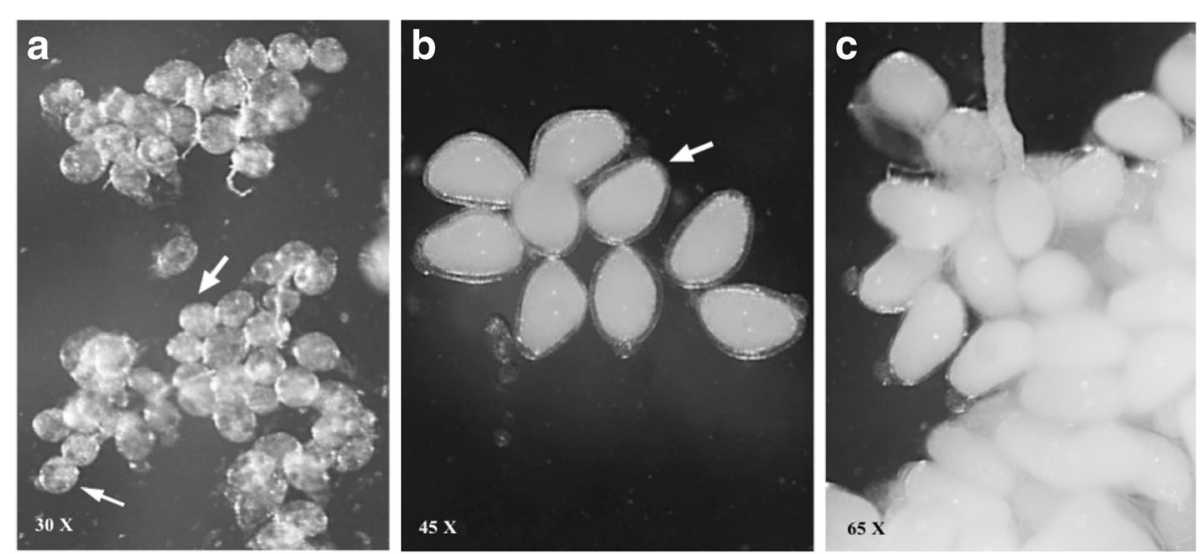

Fig. 4 Oogenesis in S. erythrocephalum. a Six hours post-feeding: ovaries in stage III (arrows indicate that yolk fills about 30-40\% of the follicular space). $\mathbf{b} 12$ to $36 \mathrm{~h}$ post-feeding: ovaries in stage IV (yolk is present throughout the follicular space). c 42 to $48 \mathrm{~h}$ post-feeding: ovaries in stage $\mathrm{V}$ (mature ovarioles) 
Europe. Cupina et al. [22, 24] indicated a tendency for this species to feed on humans over domestic animals. Jedkicka and Halgoš [25] reported a preference for horses over humans, and Crosskey [9] described this species as principally a pest of cattle and sometimes of humans.

The daily variation in landing rate has been observed in other studies [26] and may due to the existence of adult emergency waves from the breeding sites. The average of 34 lands/person/day is much higher than that classified as extreme risk (>11 S. erythrocephalum bites/ person/afternoon) in Serbia [27]. During the first three days of our study, DLR was 106, 77 and 51 lands/ person/day, above the mean DLR. The number of blackflies attacking their hosts can vary and is influenced by many factors [9]. In our study, the DLR could have increased in years when the Ebro River floods did not occur in winter and spring and, thus, did not pull up the macrophytes that provide a substrate for the preimaginal stages.

Simulium erythrocephalum showed a bimodal landingactivity pattern, with a minor peak at dawn and a major peak at dusk. Other European studies also have noted dusk as a period with a high number of bites by $S$. erythrocephalum [27, 28]. In Spain, the bimodal daily landing-activity pattern was affected by temperature and solar radiation.

With regard to solar radiation, flies showed host-seeking activity between 220.43 and $612.48 \mathrm{~W} / \mathrm{m}^{2}$ in the morning, while most host-seeking activities were concentrated below $123.51 \mathrm{~W} / \mathrm{m}^{2}$ in the evening. Host-seeking activity was greatest when the solar radiation was $0 \mathrm{~W} / \mathrm{m}^{2}$ at 20:30 $\mathrm{h}$, with the presence of a dim sunlight. Illumination is considered probably the most important external factor influencing the biting-activity pattern [9]. Flies showed host-seeking activity beyond the two peaks during cloudy periods after rain when temperature and solar radiation were within those ranges. The same behaviour was reported for S. damnosum (s.l.), which typically bites in the early morning and before dusk, but continues throughout the day during overcast weather [29, 30].

The optimal temperature for host-seeking activity of $S$. erythrocephalum was between 17.4 and $22{ }^{\circ} \mathrm{C}$ in the morning and between 22.17 and $27.35{ }^{\circ} \mathrm{C}$ in the evening. Our observations are similar to those reported by Berzina [31] within a temperature range of $15-27{ }^{\circ} \mathrm{C}$ in the Volga River Delta and $12-27{ }^{\circ} \mathrm{C}$ in the arctic. Females of $S$. erythrocephalum females were inactive when temperatures were above $29{ }^{\circ} \mathrm{C}$, even though solar radiation remained in the optimal range for the second peak of host-seeking activity.

Dawn and dusk were the high-risk periods for suffering from biting by S. erythrocephalum. The optimal period for monitoring $S$. erythrocephalum is during the pre-sunset hours when solar radiation is below $123.51 \mathrm{~W} / \mathrm{m}^{2}$, and the temperature is $22.00-27.00{ }^{\circ} \mathrm{C}$. Concentrating the efforts for adult sampling during this time can be less time and consuming and most cost effective if the evaluation of control strategies are to be implemented in Spain. HLC, along with adult trapping methods and larval monitoring at breeding sites, could be used routinely in future entomological studies in the country.

We did not evaluate the variation in the humanlanding rates from one season to another. The study was carried out in late spring (May and June 2015) because very few S. erythrocephalum females were caught using HLC during previous months. During March and April, no adults of this species were caught using HLC. The first caught of host seeking S. erythrocephalum females was during the second week of May. May and June were the most suitable months for the sampling of S. erythrocephalum in this area. Bardin [32] pointed out that discomfort due to $S$. erythrocephalum species begins in May and increases during June and July in southern France. In September 2015, few S. erythrocephalum females (1-2 females were caught using HLC at dusk each day) were observed flying, and low numbers of larvae and pupae were found at the breeding sites. This decrease in population numbers of $S$. erythrocephalum during July, August, and September has been reported in other countries of Central and North Europe [24, 33-36]. Bardin [32] reported that S. erythrocephalum produced discomfort in France from spring through October. Thus, further studies are needed to define the spatial and temporal dynamics of S. erythrocephalum in Spain.

We observed no clear daily pattern of parity. Both peaks showed high parous rates, but parity was higher during the second peak at dusk (78\%) than during the first one at dawn (56\%). The catches of recent parous females, using the HLC method, indicated that S. erythrocephalum begin to search for and locate a new host almost immediately after oviposition, as reported for $S$. ochraceum (s.l.) [37]. The estimated gonotrophic cycle length of 2 days for $S$. erythrocephalum was shorter than those reported for certain species vectors for onchocerciasis: 3 days for S. metallicum (s.l.) [38], 4 days for $S$. ochraceum (s.l.) in Central America [26, 37] and about two and a half days for S. damnosum (s.l.) in West Africa $[16,39]$. The 2-day gonotrophic cycle length was confirmed by oogenesis studies. However, Rubtsov [20] reported that the blood-meal to gravidity interval was 5-7 days for S. erythrocephalum, and Ham \& Blanco [40] reported that it was 3-5 days at room temperature.

High parity rates of $S$. erythrocephalum indicate a high survivorship rate for this anthropophilic species. Survivorship rate in S. erythrocephalum was estimated to be $85 \%$, with a daily parity rate of $72 \%$, which is higher than that reported for other species, such as $S$. ochraceum (s.l.) (80\%) in Mexico [26]. The same value of 0.85 
elevated to the 2 nd potency was $72.2 \%$, the survival rate for the second day (first gonotrophic cycle).

High rates of adult survival coupled with the short gonotrophic cycle of $S$. erythrocephalum have important implications for public health. Females of S. erythrocephalum are potentially ready for human-host seeking 2 days after blood feeding and oviposition. This implies the possibility that many bites occur and that many eggs are laid at the breeding sites in a short period. Simulium erythrocephalum has a gonotrophic cycle shorter than other aggressive European species such as the S. ornatum complex or S. lineatum, which have blood-meal to gravidity intervals of 3-5 days [40, 41]. Simulium erythrocephalum could feed twice on humans, compared with once in those species with longer gonotrophic cycles. Short gonotrophic cycle and strong anthropophilic nature together with its efficiency for locating hosts, could lead S. erythrocephalum to emerge as an important human bite nuisance insect in Spain.

\section{Conclusions}

Results indicated that S. erytrocephalum is an important anthropophilic blackfly collected by HLC method in the study region. The highest risk to suffer from S. erythrocephalum bites is during the pre-sunset hours. Human landing activity of host-seeking females of this species is greatly influenced by air temperature and solar radiation. A short gonotrophic cycle length and a high survival rate of $S$. erythrocephalum indicate a great success in the development of this species in Spain with the consequent impact on public health.

\begin{abstract}
Abbreviations
ARIMA: Auto regressive integrated moving average procedure; CEICA: Comité Ético de Investigación Clínica de Aragón; CG: Gonotrophic cycle; DHLP: Daily human-landing pattern; DLR: Daily landing rate; DPR: Daily parity rate; DSR: Daily survival rate; GLIMMIX: Generalised linear mixed model; HLC: Human landing collection; HLCP: Human landing collection periods; LSM: Least square means; PBS: Phosphate buffer solution; S: Survivorship; SR: Solar radiation; UTC: Coordinated universal time
\end{abstract}

\section{Acknowledgements}

We thank Sarah Delacour Estrella, Dr. David Martínez Duran, Ana Muñoz Otero and Paloma Pik Tuval for their assistance in the field work and logistics. We thank Dr. Pablo Miguel Lucas for his help with Fig. 1. We thank Dr. Barry McMachon and Dr. Ignacio de Blas Giral for reading an earlier version of the manuscript. We also thank Dr. Peter Adler for providing us with research papers and for his review of the final version of the manuscript. We would like to thank Dr. Teresa Gárate Ormaechea for providing administrative and laboratory facilities, reagents and supplies to conduct the present study. We appreciate the authorities of Zaragoza for providing the permit to conduct the fieldwork in the district of "La Cartuja". Partial results from this study were presented at the VII International Simuliidae Symposium held in Zaragoza, Spain, in September 2016.

\section{Funding}

Mario A. Rodríguez-Pérez held a scholarship (Reference No. 246116) from CONACYT (Mexico) to conduct sabbatical during the present study. Javier A. Garza-Hernández held a postdoctoral scholarship grant (Reference No. 291053) from Universidad Autonoma Agraria Antonio Narro, Unidad Laguna and CONACYT (Mexico) which permitted the completion of the present manuscript.

\section{Availability of data and material}

The data used in this study are included in this published article. Additional information can be requested from the corresponding author.

\section{Authors' contributions}

IRA, JAGH, FRV and MARP designed the study. IRA and JLC conducted the preliminary survey. IRA and JAGH conducted the field work. FRV performed the statistical analyses. IRA and JAGH compiled the main information and wrote the first draft of the manuscript. All authors critically reviewed and approved the submitted version.

\section{Competing interests}

The authors declare that they have no competing interests.

\section{Consent for publication \\ Not applicable.}

Ethics approval and consent to participate

Ethical clearance for HLC was obtained from the board of Ethical Committee for Clinical Research of Aragon, the Government of Aragon (CEICA) (Reference no. PI15/0147). Individual informed consent forms were signed by human volunteers serving as blackfly collectors after detailed explanations about the purpose of the study, collection procedure for host-seeking female black flies, and potential health risk during the field studies.

\section{Publisher's Note}

Springer Nature remains neutral with regard to jurisdictional claims in published maps and institutional affiliations.

\section{Author details}

${ }^{1}$ Departamento de Patología Animal, Facultad de Veterinaria, Universidad de Zaragoza, Zaragoza, Spain. ${ }^{2}$ Centro de Rickettsiosis y Enfermedades Transmitidas por Artrópodos Vectores, Centro de Investigación Biomédica de La Rioja (CIBIR), La Rioja, Spain. ${ }^{3}$ Instituto Politécnico Nacional, Centro de Biotecnología Genómica, Laboratorio de Biomedicina Molecular, Reynosa, Tamaulipas, Mexico. ${ }^{4}$ Laboratorio de Biología Molecular, Universidad Autónoma Agraria "Antonio Narro" Unidad Laguna, Coahuila, Mexico.

Received: 25 October 2016 Accepted: 27 March 2017

Published online: 08 April 2017

\section{References}

1. Adler PH. Black flies, the Simuliidae. In: Marquardt WC, editor. Biology of Disease Vectors. 2nd ed. San Diego: Elsevier Academic Press; 2005. p. 127-40.

2. Cupp EW, Cupp MS. Black fly (Diptera: Simuliidae) salivary secretions: importance in vector competence and disease. J Med Entomol. 1997;34 Suppl 2:87-94

3. Chattopadhyay P, Goyary D, Dhiman S, Rabha B, Hazarika S, Veer V. Immunomodulating effects and hypersensitivity reactions caused by Northeast Indian black fly salivary gland extract. J Immunotoxicol. 2014; $11(2): 126-32$

4. Ruiz-Arrondo I, Alarcón-Elbal PM, Figueras L, Delacour-Estrella S, Muñoz A, Kotter H, et al. Expansión de los Simúlidos (Diptera: Simuliidae) en España: Un nuevo reto para la Salud Pública y la Sanidad Animal. Bol SEA. 2014;54 193-200.

5. Ruiz-Arrondo I, Martinez E, Kotter H, Figueras L, Muñoz A, Delacour-Estrella S, et al. Blackfly outbreak in Zaragoza in 2011. Spread of blackflies in the Middle Ebro Valley in Northeast Spain. In: Kúdela M, Stloukalová V, editors. Programme and Abstract Book. 5th International Simuliid Symposium. Bratislava: Faculty of Natural Sciences, Comenius University; 2012.

6. Adler PH, Seitz G. Chromosomal characteristics and evolutionary relationships of the Palearctic black fly Simulium carthusiense (Diptera: Simuliidae). Eur J Entomol. 2014;111(4):469-74. doi:10.14411/eje.2014.066.

7. Adler PH, Crosskey RW. World blackflies (Diptera: Simuliidae): a comprehensive revision of the taxonomic and geographical inventory. 2016 https://www.clemson.edu/cafls/biomia/pdfs/blackflyinventory.pdf. Accessed 15 Sept 2016.

8. Ham PJ, Bianco AE. Development of Onchocerca volvulus from cryopreserved microfilariae in three temperate species of laboratory-reared blackflies. Tropenmed Parasitol. 1983:34(2):137-9.

9. Crosskey RW. The Natural History of Black Flies. Chichester: Wiley; 1990. 
10. Mikhailyuk AP. Study of the biology of the causative agent of cattle onchocerciasis in forest-steppe zone conditions of the Ukrainian SSR. Veterinariya. 1967;11:62-7.

11. Ruiz-Arrondo I, Kotter H, Rueda J, Ortíz A, Gómez P, Marqués E, et al. Expansion of simulids (Diptera: Simuliidae) in Spain. In: Bueno R editor. Final Programme and Abstract Book. 7th Conference European Mosquito Control Association. 23-26 February. Valencia, Spain. 2015.

12. Figueroa $\mathrm{MH}$, Collins $\mathrm{RC}$, Kozek WH. Postprandial transportation and maintenance of Simulium ochraceum infected with Onchocerca volvulus. Am J Trop Med Hyg. 1977;26:75-9.

13. Kettle DS, Linley JR. The biting habits of Leptoconops bequaerti. I. Methods; standardization of technique; preferences for individuals, limbs and positions. J Appl Ecol. 1967;4:379-95.

14. Cupp EW, Collins RC. The gonotrophic cycle in Simulium ochraceum. Am J Trop Med Hyg. 1979;28:422-6.

15. Mutero C, Birley M. Estimation of the survival rate and oviposition cycle of field populations of malaria vectors in Kenya. J Appl Ecol. 1987;24:853-63.

16. Holmes PR, Birley MH. An improved method for survival rate analysis from time series of haematophagous dipteran populations. J Anim Ecol. 1987;56: 427-40.

17. Davidson G. Estimation of the survival rate of anopheline mosquitoes in nature. Nature. 1954;174:792-3.

18. Christophers SR. The development of the egg follicle in anophelines. Paludism. 1911;2:73-88

19. Clements A. The biology of mosquitoes, Vol 1. Development, nutrition and reproduction. London: Chapman and Hall; 1992.

20. Rubtsov IA. The gonotrophic cycle in bloodsucking black flies. Parazitol Sbornik. 1958;18:255-82.

21. Werner D, Kampen H. Simulium (Boophthora) erythrocephalum (De Geer, 1776), subgenus and species new to Armenia. Zool Middle East. 2012;56:8590. doi:10.1080/09397140.2012.10648944.

22. Ignjatović-Ćupina A, Petrić D, Zgomba M, Marinković D, Konjević A. Black flies (Diptera: Simuliidae) of the Fruška Gora Mountain. In: Simic S, editor. Invertebrates (Invertebrata) of the Fruška Gora Mountain. Novi Sad: Matica Srpska; 2013. p. 125-63.

23. Živković V, Burány B. An outbreak of Boophthora erythrocephala (Diptera, Simuliidae) in Yugoslavia in 1970. Acta Vet. 1972;22:133-42.

24. Ignjatović-Ćupina A, Zgomba M, Vujanović LJ, Konjević A, Marinković D, Petrić D. An outbreak of Simulium erythrocephalum (De Geer, 1776) in the region of Novi Sad (Serbia) in 2006. Acta Entomol Serbica. 2006; Suppl:97-114.

25. Halgoš J, Jedlička L. The black flies (Diptera, Simuliidae) attacking horses in the environs of Bratislava. Biologia. 1971;26(5):431-3.

26. Rodríguez-Pérez MA, Reyes-Villanueva F, Rodríguez MH. Estimating the gonotrophic cycle and survivorship of Simulium ochraceum (Diptera: Simuliidae) during routine vector surveillance in southern Mexico. J Am Mosq Control Assoc. 1995;11:360-2.

27. Ignjatović-Ćupina A, Petrić D, Zgomba M, Konjević A, Grabovac S, Marinković D. Estimating the biting risk to humans by the black fly species that are most abundant in the region of Novi Sad (Vojvodina Province, Serbia and Montenegro). In: Werner D. editor. Papers on the taxonomy, ecology and biology of black flies (Diptera: Simuliidae). Studia Dipterol. 2006; Suppl 14:31-44.

28. Jedlička L, Halgoš J. Daily biting rate of black flies on horses in the Danubian lowlands (Diptera, Simuliidae). Wiodomošci Parazytol. 1982;28:1-2.

29. Van Den Berghe L. Recherches sur l'Onchocercose au Congo Belge, la transmission d'Onchocerca volvulus parles Simulies. Ann Soc Belg Med Trop. 1941;21:63-76.

30. Fallis AM. Feeding and related behavior of female Simuliidae (Dipiera). Exper Parasitol. 1964;15:439-70.

31. Berzina AN. Attack by blackflies on man in nature. Parazitol Sbornik. 1953;15: 353-85.

32. Bardin O. Nuisance due to Simulium (Boophthora) erythrocephalum (De Geer 1776) (Diptera, Simuliidae) in France. Parasite. 2001;8:161-2.

33. Ruhm W. Zur Populationsdynamik der Kriebelmucken, insbesondere von Boophthora erythrocephala de Geer und des Odagmia ornata-komplexes. Z Angew Entomol. 1969;63:212-27.

34. Post RJ. The annual cycle of Simulium erythrocephalum (Diptera: Simuliidae) at a site in Norfolk. Freshwater Biol. 1983;13:379-88.

35. Werner D. Kriebelmücken (Simuliidae) - Informationsbroschüre zur Morphologie, Lebensweise und Verbreitung der Kriebelmücken unter Berücksichtigung der Schadregionen in Deutschland sowie des
Krankheitsbildes Simuliose und des Schadbildes Simuliotoxikose. Stud Dipterol. 2007;3:337-58.

36. Bernotiene R, Bartkeviciene $\mathrm{G}$. The relationship between water temperature and the development cycle beginning and duration in three black fly species. J Insect Sci. 2012;13(1):1-15.

37. Porter $\mathrm{CH}$, Collins RC. The gonotrophic cycle of wild Simulium ochraceum and the associated development of Onchocerca volvulus. Am J Trop Med Hyg. 1985;34:302-9.

38. Rodríguez-Pérez MA, Vázquez-Sánchez R, Reyes-Villanueva F. Estimation of survival and gonotrophic cycle length of Simulium metallicum sensu lato (Diptera: Simuliidae) in Southern Mexico. J Am Mosq Control Assoc. 2001; 17(4):254-9

39. Cheke RA. Cycles in daily catches of members of the Simulium damnosum species complex. Trop Med Parasitol. 1995;46(4):247-52.

40. Ham PJ, Blanco AE. Maintenance of Simulium Wilhelmia lineatum Meigen and Simulium erythrocephalum de Geer through successive generations in the laboratory. Can J Zool. 1984;62:870-7.

41. Davies L. A study of the blackfly, Simulium ornatum Mg. (Diptera), with particular reference to its activity on grazing cattle. Bull Entomol Res. 1957; 48:407-24.

\section{Submit your next manuscript to BioMed Central and we will help you at every step:}

- We accept pre-submission inquiries

- Our selector tool helps you to find the most relevant journal

- We provide round the clock customer support

- Convenient online submission

- Thorough peer review

- Inclusion in PubMed and all major indexing services

- Maximum visibility for your research

Submit your manuscript at www.biomedcentral.com/submit
) Biomed Central 